\title{
Seasonal Variation in Intensity of Bud Dormancy in Apple Cultivars and Related Malus Species
}

\author{
Roberto Hauagge ${ }^{1}$ and James N. Cummins \\ Department of Horticultural Sciences, New York State Agricultural Experiment Station, Cornell \\ University, Geneva, NY 14456
}

Additional index words. chilling, chilling efficiency, dormancy induction, dormancy intensity, end of dormancy, rest, subtropics

\begin{abstract}
Dormancy patterns throughout the season were studied in more than 90 apple (Malus $\times$ domestica Borkh.) cultivars and related Malus spp. The seasonal apple bud dormancy pattern resembles a normal curve: it starts to intensify soon after bud formation and reaches maximum intensity by the time of leaf fall/senescence. Genotypes were grouped into three general classes based on maximum dormancy intensity. Maximum intensity of bud dormancy measured in cold winters is inversely related to adaptation to the subtropics. Low-chilling requirement (CR) cultivars have a shallow depth of dormancy with very little alteration throughout the year. High-CR cultivars have intense bud dormancy, the first stage of which can be induced by growing these cultivars at temperatures above $20 \mathrm{C}$. Genotypes differed in their rates of dormancy dissipation. The efficiency of chilling unit $(\mathrm{CU})$ accumulation to break dormancy was negatively correlated with CR, which indicates the importance of factors other than CU accumulation in terminating bud dormancy in low-CR cultivars. The inherent length of bud dormancy plays a major role in determining the time of budbreak in the spring. Deviations may be related to the genotypic efficiency in which chilling modifies dormancy and possibly the basal temperatures to which buds respond. Chill unit requirement and heat unit requirement are dependent factors. Heat requirement comparisons may be meaningless if the dormancy intensities of the genotypes are not taken into consideration.
\end{abstract}

The seasonal apple bud dormancy pattern (Latimer and Robitaille, 1981; Williams et al., 1979), as well as bud dormancy patterns of other species, such as Prunus armeniaca L., $P$. persica L. (Hatch and Walker, 1969), Cornus stolonifera (Fuchigami et al., 1977), and Carya spp. (Amling and Amling, 1980), resembles a normal curve. Dormancy reaches a maximum and then gradually decreases with the accumulation of low temperatures. The fact that dormancy is a continuous process has sometimes been overlooked. Additional chilling accumulation will continuously shorten the time for budbreak and increase growth. This seems to be a general phenomenon, observed in a wide range of plants, including Rubus spp. (Bailey, 1948), Picea abies (L.) Karst (Worral and Mergen, 1967), Malus spp. (Couvillon and Erez, 1985; Landsberg, 1974; Powell, 1986; Shaltout and Unrath, 1983; Swartz and Powell, 1981; Tabuenca, 1983; Tabuenca and Jiménez, 1984; Thompson et al., 1974), Prunus persica (Couvillon and Erez, 1985; Couvillon and Hendershott, 1974; Scalabrelli and Couvillon; 1986), Carya spp. (Amling and Amling, 1980), Abies fraseri (Hinesley, 1982), Prunus avium L. (Couvillon and Erez, 1985), and Pyrus spp. (Couvillon and Erez, 1985). The mathematics interpretation of the phenomenon was probably first described by Worral and Mergen (1967) for Picea abies. The fitting of either a line (Couvillon and Hendershott, 1974; Tabuenca and Jiménez, 1984), a parabola (Couvillon and Erez, 1985; Worral and Mergen, 1967), or a hyperbola (Landsberg, 1974) will largely depend on how wide the experimental observations are in relation to the chilling accumulation.

The CR requirement is a characteristic generally used to compare genotypes in relation to the termination of the dormancy

\footnotetext{
Received for publication 1 Aug. 1989. We thank L.E. Powell and R.D. Way for critical review of this manuscript, and R.D. Way and R.C. Lamb for providing apple shoots from the apple collection at Geneva, N.Y. The cost of publishing this paper was defrayed in part by the payment of page charges. Under postal regulations, this paper therefore must be hereby marked advertisement solely to indicate this fact.

'Present address: IAPAR-Instituto Agronômico do Paraná P.O. Box 2301, Curitiba, PR, Brazil 80001.
}

period. It is a valid criterion but takes into consideration only one point in the dormancy dissipation curve. The purpose of our work was to verify the variability of the apple bud dormancy pattern in many apple cultivars and related species throughout the season and to determine how this pattern is related to both the end of dormancy as conventionally defined and to the genotypic adaptation to environmental conditions that affect the length of bud dormancy. The relationship among the different indices used to estimate the end of dormancy (Hauagge and Cummins, 1991a), as well as the length of dormancy period in apple cultivars and related species growing under cold and subtropical winters (Hauagge and Cummins, 1991b), are subjects of companion papers.

\section{Materials and Methods}

Field sampling. Previous season's apple shoots 15 to $25 \mathrm{~cm}$ long and having terminal flower buds were collected periodically from trees growing at the New York State Agricultural Experiment Station, Geneva, during the 1984-85 (20 sampling times between 22 Oct. 1984 and 27 Mar. 1985), 1985-86 (16 sampling times between 24 Sept. 1985 and 28 Apr. 1986), and 1986-87 (12 sampling times between 14 July 1986 and 13 Apr. 1987) fall/winter seasons. Leaves were removed when necessary, and shoots were forced in continuous light and at constant temperature $(23 \pm 1 \mathrm{C}$ in $1984-85$ and $1985-86$; $19 \pm 1 \mathrm{C}$ in 1986-87). Shoots with terminal buds removed were also used on five sampling dates in the 1986-87 experiments. Shoots were completely randomized, with four shoots in each of four replications. The day in which $50 \%$ of shoots had terminal (or uppermost) buds broken, i.e., when buds reached greentip (Chapman and Catlin, 1976), was monitored in the 1985-86 (within 21 days of forcing) and 1986-87 (35 to 180 days of forcing) seasons. Dormancy intensity, as defined in this study, is the number of days under forcing conditions needed for $50 \%$ of shoots to have terminal budbreak (D50). Generally, more than 90 geno-

$\overline{\text { Abbreviations: }} \mathrm{CR}$, chilling requirement; $\mathrm{CU}$, chill unit; D50, number of days for $50 \%$ terminal budbreak; GDH, growing degree hours. 


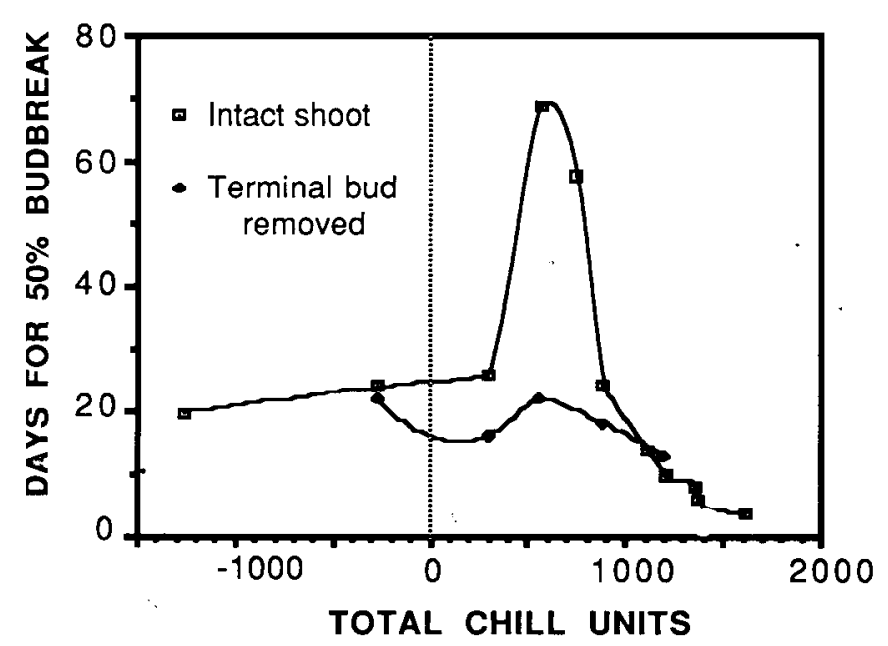

Fig. 1. General mean bud dormancy pattern in intact (terminal buds) and decapitated (uppermost buds) apple shoots. The means were calculated based on 94 and 80 genotypes, respectively. Sampling on 14 July and 1 Sept. 1986 corresponded to -1276 CU and -283 $\mathrm{CU}$, respectively. Shoots were collected from the field and forced in continuous light at $19 \pm 1 \mathrm{C}$.

types were evaluated each year. Shoot collection, forcing procedures, CU, and GDH accumulation were described earlier (Hauagge and Cummins, 1991a, 1991 b).

Dormancy development under high- and low-temperature environments. Recently grafted plants of the cultivars Anna, Ein Shemer, Golden Delicious, and Koningszuur were planted in the greenhouse on 30, May 1985. At least 10 plants of each cultivar were subjected to each of the following treatments: a) Trees were grown in a greenhouse at temperatures above 20C and bud dormancy was induced followed by forcing. Dormancy was induced by a process modified from Stushnoff (personal communication) in which temperature was maintained at $14 \pm$ $2 \mathrm{C}, 8 \pm 2 \mathrm{C}$, and $14 \pm 2 \mathrm{C}$ for 20 , 40, and 14 days, respectively, starting 180 days after grafting (Hauagge and Cummins, $1991 \mathrm{~b}$ ). At the end of the dormancy induction treatment, $80 \%$ to $95 \%$ of the leaves on all plants had abscised or were in an maintained above 20C, and the plants were hand-defoliated either on 20 Nov. 1985 or c) 29 Mar. 1986, 180 and 300 days after planting, respectively. Plants of all three treatments were evaluated for their growth response by the degree of adaptation (Hauagge and Cummins, 1991b) after 30 days of forcing at 22 $\pm 1 \mathrm{C}$ and $16 \mathrm{~h}$ of light. Degree of adaptation was an index based on the intensity of delayed foliation symptoms displayed by the plants after forcing. Classes $(0=$ completely dormant, and $5=$ no symptoms of delayed foliation) were based on the number of buds broken, uniformity of budbreak, and internode elongation.

\section{Results and Discussion}

The mean bud dormancy pattern observed in both intact ( 94 genotypes) and decapitated (80 genotypes) apple twigs in 198687 for all Malus cultivars and species studied is shown in Fig. 1. In 1986, budbreak observations could be carried out only during 35, 53, 114, and 180 days of forcing, i.e., for sampling, on 14 July 1986 (-1276 CU), 1 Sept. 1986 (-282 CU), 22 Oct. 1986 (288 CU), and 10 Nov. 1986 (556 CU), respectively, because of incomplete shoot maturity at the early dates. Some cultivars did not show budbreak after 180 days of forcing. Conadvanced stage of senescence. b) Temperature was always

Table 1. Classification of apple cultivars and related Malus spp. according to the maximum bud dormancy intensity observed in the 1986-87 season. ${ }^{2}$

\begin{tabular}{|c|c|}
\hline Dormancy intensity & Days to D50 \\
\hline \multicolumn{2}{|l|}{ 1. Shallow } \\
\hline Anna $a^{y, x}$ & $13.8^{w}$ \\
\hline Dorsett Golden ${ }^{y}$ & $30.0^{\mathrm{w}}$ \\
\hline Ein Shemer ${ }^{y}$ & $31.7^{w}$ \\
\hline$M$. brevipes ${ }^{y, \mathrm{x}}$ & $17.2^{v}$ \\
\hline M. baccata mandshurica & $34.0^{\mathrm{w}}$ \\
\hline M. prunifolia DE\#229y & $28.5^{u}$ \\
\hline M. prunifolia xanthocarpa & $20.7^{t}$ \\
\hline M. rockii ${ }^{\mathrm{y}, \mathrm{x}}$ & $23.6^{w}$ \\
\hline M. spectabilis ${ }^{y, x}$ & $19.0^{\mathrm{w}}$ \\
\hline M. sylvestris PI $392302^{y}$ & $19.0^{\mathrm{w}}$ \\
\hline M. $\times$ arnoldiana ${ }^{\mathrm{y}}$ & $32.0^{\mathrm{w}}$ \\
\hline M. $\times$ magdeburgensis & $30.0^{\mathrm{w}}$ \\
\hline M. $\times$ scheideckeri $^{\mathrm{x}}$ & $31.2^{\mathrm{w}}$ \\
\hline Zabaoanix & $34.0^{\mathrm{v}}$ \\
\hline \multicolumn{2}{|l|}{ 2. Medium } \\
\hline Coast $^{y}$ & $>35^{w}$ \\
\hline Governor Carr & $>35^{w}$ \\
\hline Granny Smith & $60.5^{v}$ \\
\hline Idared & $75.0^{\mathrm{w}}$ \\
\hline Joan & $45.0^{t}$ \\
\hline Leyda & $42.0^{u}$ \\
\hline M. baccata (PI 392301)y & $>35^{w}$ \\
\hline M. baccata DE\#98 & $48.7^{\vee}$ \\
\hline M. baccata Ge24911 & $44.5^{v}$ \\
\hline M. baccata columnaris & $56.2^{v}$ \\
\hline M. prunifolia 'Sikora I' & $52.5^{\mathrm{w}}$ \\
\hline M. turesii PI 34143 & $35.0^{\mathrm{w}}$ \\
\hline M. zumi calocarpa & $86.7^{v}$ \\
\hline M. $\times$ robusta DE\#485 & $84.0^{\mathrm{w}}$ \\
\hline M. $\times$ robusta 'Korea' & $78.5^{v}$ \\
\hline M. $\times$ robusta ' $\mathrm{R} 5$ ' & $72.0^{v}$ \\
\hline NY 724 & $57.0^{\circ}$ \\
\hline Rosedale ${ }^{x}$ & $37.2^{t}$ \\
\hline Toba & $48.0^{4}$ \\
\hline Viennay & $91.5^{v}$ \\
\hline Winter Bananay & $35.0^{t}$ \\
\hline \multicolumn{2}{|l|}{ 3. Deep } \\
\hline Anoka & $>170^{v}$ \\
\hline Arkad Zimnji & $159.0^{\mathrm{v}}$ \\
\hline Beverly Hills & $>170^{\circ}$ \\
\hline Blairmont & $140.0^{\vee}$ \\
\hline Carla & $>114^{\mathrm{v}}$ \\
\hline Cherry Cox & $150.0^{v}$ \\
\hline Chihuahua Gold & $135.0^{\mathrm{v}}$ \\
\hline Dakota & $>170^{v}$ \\
\hline Delicious & $>170^{\circ}$ \\
\hline Early McIntosh & $>170^{v}$ \\
\hline Elstar & $133.5^{v}$ \\
\hline Empire & $154.7^{\mathrm{v}}$ \\
\hline Fuji & $117.0^{\mathrm{v}}$ \\
\hline Gala & $>170^{2}$ \\
\hline Golden Delicious & $129.0^{\mathrm{v}}$ \\
\hline Honeygold & $141.3^{v}$ \\
\hline Hyslop & $112.7^{\mathrm{v}}$ \\
\hline Ikorocavka Alaja & $107.0^{v}$ \\
\hline Irish Peach & $150.0^{\mathrm{v}}$ \\
\hline June Wealthy & $99.0^{\mathrm{v}}$ \\
\hline Kerr & $109.7^{\imath}$ \\
\hline King Cole & $>170^{v}$ \\
\hline Koningszuur & $>170^{\circ}$ \\
\hline Liberty & $>170^{\circ}$ \\
\hline M. baccata $\mathrm{Ge} 24408$ & $135.3^{v}$ \\
\hline M. baccata 'Nertschinsk' & $101.5^{\mathrm{t}}$ \\
\hline
\end{tabular}


Table 1. (continued)

\begin{tabular}{|c|c|c|}
\hline Dormancy intensity & & Days to D50 \\
\hline M. prunifolia rinkii & & $167.0^{\mathrm{v}}$ \\
\hline Maribor & & $>170^{\vee}$ \\
\hline McIntosh & & $>170^{\vee}$ \\
\hline Medina & & $>170^{\circ}$ \\
\hline Melrose & & $>170^{\mathrm{v}}$ \\
\hline Minkler & & $158.7^{\vee}$ \\
\hline Mollie's Delicious & & $>114^{t}$ \\
\hline N.J. 88 & & $>170^{v}$ \\
\hline Northern Spy & & $>170^{\mathrm{v}}$ \\
\hline NY $10^{\circ}$ & & $128.0^{\circ}$ \\
\hline NY 454 & 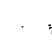 & $>114^{v}$ \\
\hline NY 480 & & $>170^{\vee}$ \\
\hline NY 485 & & $>170^{v}$ \\
\hline NY 506 & & $>114^{v}$ \\
\hline NY 543 & & $182.5^{v}$ \\
\hline NY 615 & & $>170^{v}$ \\
\hline NY 701 & & $125.0^{\mathrm{v}}$ \\
\hline NY 702 & & $>114^{\prime}$ \\
\hline NY 725 & & $>170^{\circ}$ \\
\hline Ottawa 7 & & $>170^{\circ}$ \\
\hline Prima & & $>170^{\circ}$ \\
\hline Priscilla & & $>170^{\circ}$ \\
\hline Rome Beauty & . & $170^{2}$ \\
\hline Rozovoe & & $>170^{v}$ \\
\hline Starkspur Golden Delicious & & $>170^{\circ}$ \\
\hline Stayman & & $159^{v}$ \\
\hline Transcendent & & $105^{v}$ \\
\hline Wright \#1 & & $>170^{\vee}$ \\
\hline
\end{tabular}

${ }^{2}$ Bud dormancy intensity classes were arbitrarily divided in shallow ( $<35$ days to D50), medium (35 to 100 days to D50), and deep ( >100 days to D50) dormancy intensity.

"Mean bud developmental stage was larger than 1 (green tip) after 21 days of forcing in all sampling dates in the 1984-85 season. The cultivar Khashabi also fell into this group.

${ }^{*} 50 \%$ of terminal buds broke dormancy within 21 days of forcing in all sampling dates in the 1985-86 season. The cultivars Khashabi and Lennoxville also fell into this group.

w,v...t Maximum dormancy intensity observed on 1 Sept., 10 Nov., 28 Nov., and 22 Oct. sampling dates, respectively.

sequently, the true mean of these sampling data should be higher than that presented (Fig. 1), but the pattern would not be markedly altered. Negative CU values do not have a known meaning, but they were used for simplicity.

General bud dormancy pattern. An accentuated terminal bud dormancy pattern was observed in the intact shoots (Fig. 1). Most of the cultivars showed significant dormancy intensity by the 1 Sept. 1986 sampling, and a few even on 14 July. At these times, plants in the field had not yet experienced chilling temperatures. Significant increases in dormancy intensity started to occur after the first frost and the beginning of $\mathrm{CU}$ accumulation.

Complete leaf senescence, as based on leaf color and advanced leaf abscission, was observed for all genotypes by 10 Nov. 1986. This stage corresponds approximately to the point at which maximum dormancy intensity occurred for the majority of the plants studied. Some of the species and hybrids may have shown deeper dormancy earlier (M. ×arnoldiana, M. baccata PI 392301, M. ×magdeburgensis, M. baccata mandshurica, M. ×scheideckeri DE\#316, M. spectabilis, M. turesii PI 34143, and 'Rosedale') (Table 1). On 22 Ott., 20 days earlier, the apple cultivars and related species had $30 \%$ to $50 \%$ and $70 \%$, respectively, of their leaves in an advanced stage of senescence.

Throughout the season, the general patterns of terminal bud

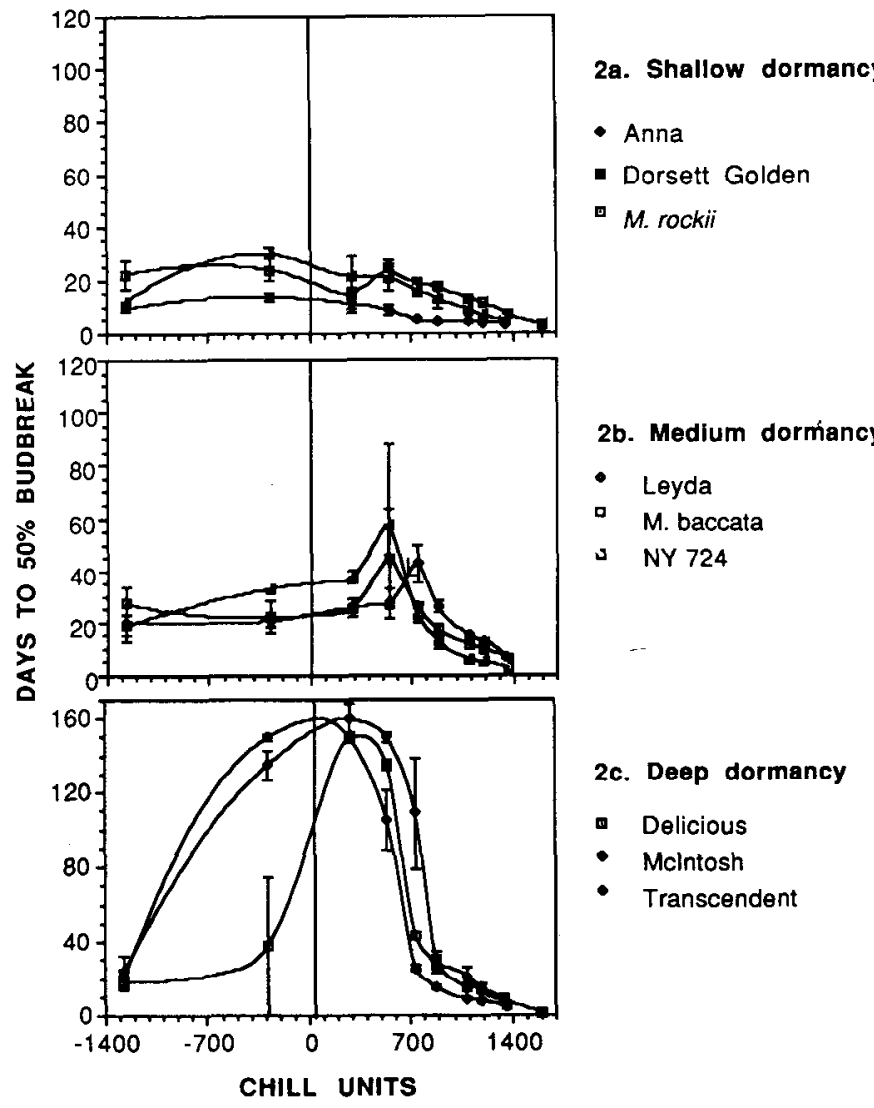

Fig. 2. Apple bud dormancy pattern general groups. Groups were arbitrarily divided according to the maximum number of days to D50 in shallow ( $<35$ days), intermediate ( 35 to 100 days), and deep (> 100 days) bud dormancy intensity. Sampling on 14 July and 1 Sept. 1986 corresponded to $-1276 \mathrm{CU}$ and $-238 \mathrm{CU}$, respectively.

dormancy varied among genotypes. They were grouped into three arbitrary classes, based on maximum dormancy intensity ( $<35$ days, between 35 and 100 days, and $>100$ days to reach $50 \%$ budbreak (D50) during forcing at any time during dormancy). These classes were observed in "domestics"-type cultivars and related species and hybrids (Fig. 2).

The first (Fig. 2a) and second groups (Fig. 2b) are characterized by the presence of shallow and intermediate dormancy throughout the year. Dormancy did not significantly change intensity in the first group, but it may have intensified in the second after CU started to accumulate, although only slightly. All the domestics-type apples included in the first group (Table 1) are known for having excellent adaptation to subtropical conditions (Miller and Baker, 1982; Samish and Lavee, 1962). Some of the species in this group (M. brevipes, M. spectabilis, and M. rockii) also have good adaptation to an alternating-temperature regime (Hauagge and Cummins, 1991b) and would certainly behave well under subtropical climates. Observations in 1984-85 and 1985-86 were consistent (data not shown). The genotypes 'Coast', 'Governor Carr', 'Granny Smith', M. baccata DE\#98, M. turesii, M. xrobusta DE\#485, 'Rosedale', and 'Winter Banana', all belonging to the second dormancy group, have better adaptation to subtropical climate than standard apple cultivars (Hauagge and Cummins, 1991b; Miller and Baker, 1982), although not as good as the first group. Some $M$. baccata clones and hybrids, of which representatives are in this group, display similar behavior (Chandler and Brown, 1957; Popenoe and Benitez, 1965; Stebbins and Walheim, 1981). 
Table 2. Onset and changes in the bud dormancy intensity in 'Anna', 'Ein Shemer', 'Golden Delicious', and 'Koningszuur' apples affected by the length of the growing season and low-temperature dormancy induction treatment at the end of the growing season. Trees were planted in the greenhouse on 30 May 1985 and temperature was maintained above $20 \mathrm{C}$ until the treatments started. Plants were defoliated (1 and 2) or dormancy was induced (3) before forcing. Dormancy status was evaluated after 30 days of forcing at 22 $\pm 1 \mathrm{C}$ and $16 \mathrm{~h}$ of light.

\begin{tabular}{lcc}
\hline Cultivar & Lateral budbreak (\%) & Dormancy statu \\
\hline \multicolumn{4}{c}{ 1. Defoliation on 20 Nov. 1985} \\
Anna & $27.3 \pm 20.9$ & $3.7 \pm 0.4$ \\
Ein Shemer & $11.0 \pm 4.9$ & $3.0 \pm 0.2$ \\
Golden Delicious & $4.5 \pm 3.9$ & $0.5 \pm 0.3$ \\
Koningszuur & $0.0 \pm 0.0$ & $0.0 \pm 0.0$ \\
& 2. Defoliation on 29 Mar. 1986 \\
Anna & $49.3 \pm 6.6$ & \\
Ein Shemer & $43.2 \pm 9.2$ & $5.0 \pm 0.0$ \\
Golden Delicious & $7.8 \pm 3.7$ & $1.0 \pm 0.0$ \\
Koningszuur & $4.9 \pm 4.4$ & $0.4 \pm 0.3$ \\
& & \\
Anna & & \\
Ein Shemer & & $4.0 \pm 0.5$ \\
Golden Delicious & & $3.4 \pm 0.5$ \\
Koningszuur & & $0.0 \pm 0.0$ \\
\hline After dormancy inductiony & $0.0 \pm 0.0$ \\
\hline
\end{tabular}

${ }^{2}$ Assessed by degree of adaptation, where $5=$ no symptoms of delayed foliation and $0=$ completely dormant; mean \pm SD.

Temperature was changed to $14 \pm 2 \mathrm{C}, 8 \pm 2 \mathrm{C}$, and $14 \pm 2 \mathrm{C}$ for 20, 40, and 14 days, respectively, starting on 20 Nov. 1985 before forcing.

The third class of dormancy pattern (Fig. 2c) is characterized both by abrupt changes and by very intense dormancy at a certain point. Almost all standard apple cultivars studied fell into this class (Table 1). They showed intense response to CU accumulation, both when entering dormancy and when emerging from -it. 'Hyslop' and 'Transcendent', which respond relatively well under subtropical conditions, are either located close to the lower end of dormancy depth, or they have shorter bud dormancy periods. We conclude that maximum bud dormancy intensity measured in cold winters is inversely related to adaptation to subtropical climates. Both 'Beverly Hills' and 'Gala' have accentuated dormancy, as in class 3 . Their partial resist ante to delayed foliation may be due to another, unknown type of response. Open-pollinated seeds of 'Gala', after alternative-temperature stratification, germinated more rapidly than those of 'Golden Delicious', although seeds of both cultivars required the same length of stratification at constant $4 \mathrm{C}$ (data not shown). Less susceptibility to chilling negation could then be a third mechanism by which genotypes may differ. This would provide adaptative advantage under a mild winter environment. Indeed, data from Bowen and Derickson (1978) and Erez et al. (1979) suggest this.

Onset of bud dormancy and changes in bud dormancy intensity affected by time and temperature. Intensification of bud dormancy in apple may start before low temperatures are experienced (Fig. 2). Hand defoliation of 'Golden Delicious' and 'Koningszuur' that had always been maintained above 20C showed that they were already in an advanced stage of dormancy (Table 2). Severe resetting was observed in the buds that broke. In contrast, 'Anna' and 'Ein Shemer' always grew promptly without any sign of resetting. Indeed, a possible interpretation from Jonkers' (1979) work is that temperatures above 18C are needed

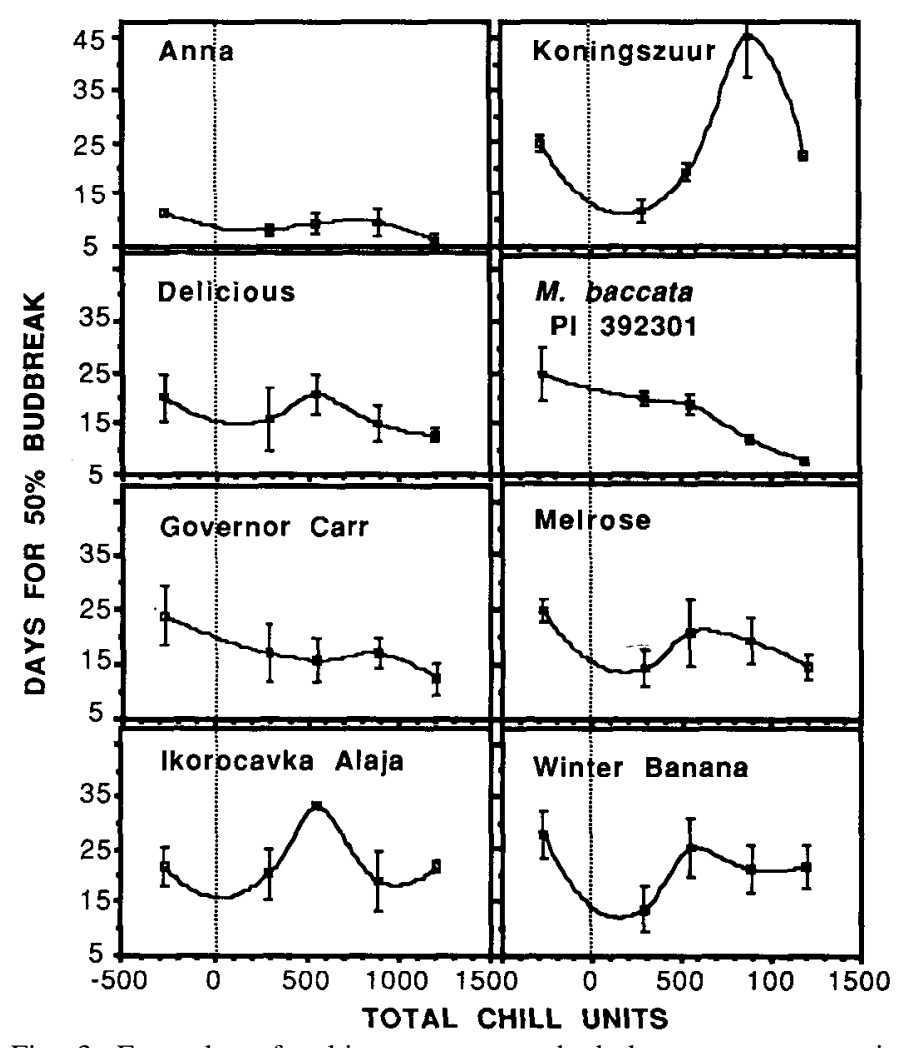

Fig. 3. Examples of cultivar uppermost bud dormancy patterns in excised decapitated shoots. Sampling on 1 Sept. 1986 corresponded to $-285 \mathrm{CU}$. Shoots were collected from the field and forced in continuous light at $19 \pm 1 \mathrm{C}$.

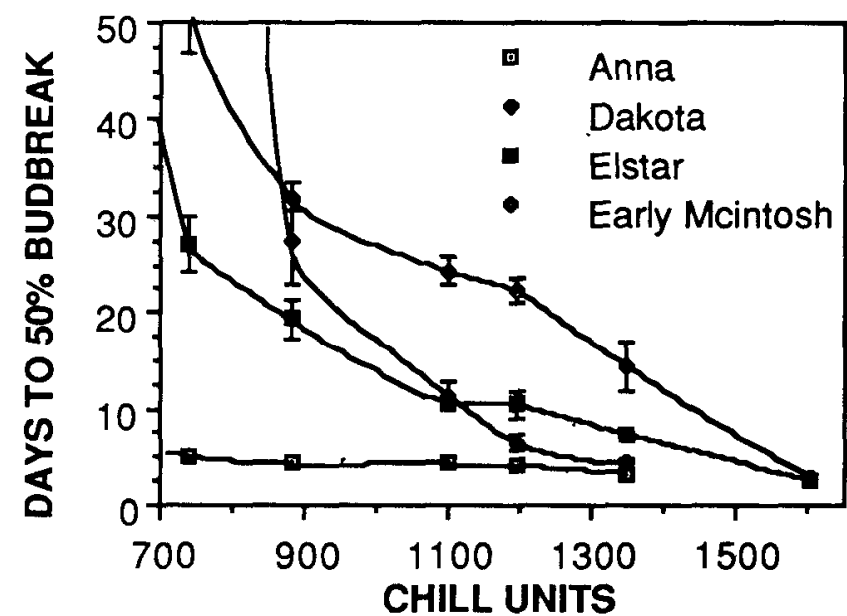

Fig. 4. Bud dormancy intensity (number of days to $50 \%$ terminal budbreak) changes at the end of the dormancy period.

to induce bud dormancy in apple. Since high temperatures induced dormancy in high-CR cultivars, it can be inferred that low chillers, such as 'Anna' and 'Ein Shemer', are unable to respond to high temperatures in the same manner. 'Dorsett Golden' trees stopped growing and shed their leaves late in Winter 198586 and 1986-87. This also has been observed in other species, such as Prunus persica (Mowrey and Sherman, 1986).

Low temperatures that are applied during dormancy development treatment can intensify dormancy (Table 2), as also observed in other species, including Carya spp. (An-ding and Amling, 1980), Cornus sericea (Kobayashi et al., 1982), and Flaxinus excelsior L. (Lavarenne et al., 1980). This phenom- 


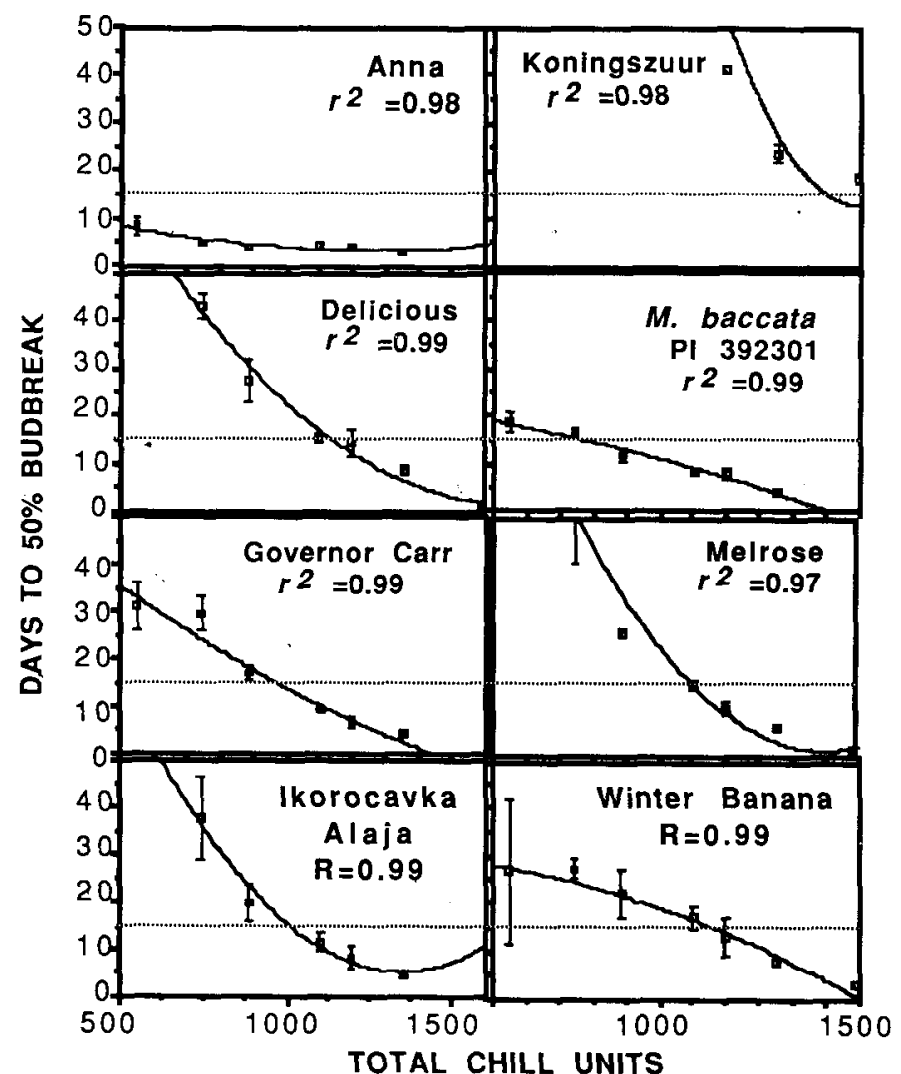

Fig.5. Changes in the number of days to $50 \%$ budbreak in terminal apple buds as affected by both cultivar and total CU accumulation. Regression coefficients were significantly different from zero at $P$ $=0.01$.

enon may suggest a two-stage dormancy induction process. Hardiness, which is developed concomitantly at time of dormancy development, is also a two-step phenomenon.

Vegetative budbreak was improved by defoliating the plants on 29 Mar. 1986 (Table 2), even when no temperatures below 20C were experienced. Many 'Anna' lateral buds grew even without defoliation after 10 Apr. 1986 (data not shown). Small budbreak differences between high- and low-CR cultivars also occurred when hand defoliation was done before terminal buds had formed (data not shown).

These findings support the thesis that low-chilling cultivars, such as 'Anna' and 'Ein Shemer', never enter deep dormancy and that low temperatures are not required to break their bud dormancy. The general improvement of budbreak by delaying hand defoliation could be the result of better and more uniform bud development. It also may indicate that the dormancy-breaking process develops even at high temperature, but at a low rate. Considerable increase in lateral flower bud formation was observed by delaying defoliation. Physiological differences that may exist between high- and low-CR groups of genotypes, especially between groups 1 and 3 , must begin during the induction of the bud dormancy process during summer.

Uppermost bud domrancy pattern in decapitated shoots. In contrast to the behavior of terminal buds of excised intact shoots, general changes in dormancy in the uppermost buds of excised shoots whose terminal buds had been removed did not follow a clear pattern (Fig. 1). The dormancy patterns in specific cultivars, except for a few, such as 'Koningszuur', a very high-CR cultivar, did not show any marked feature (Fig. 3). In this case, the maximum bud dormancy intensity was markedly delayed.

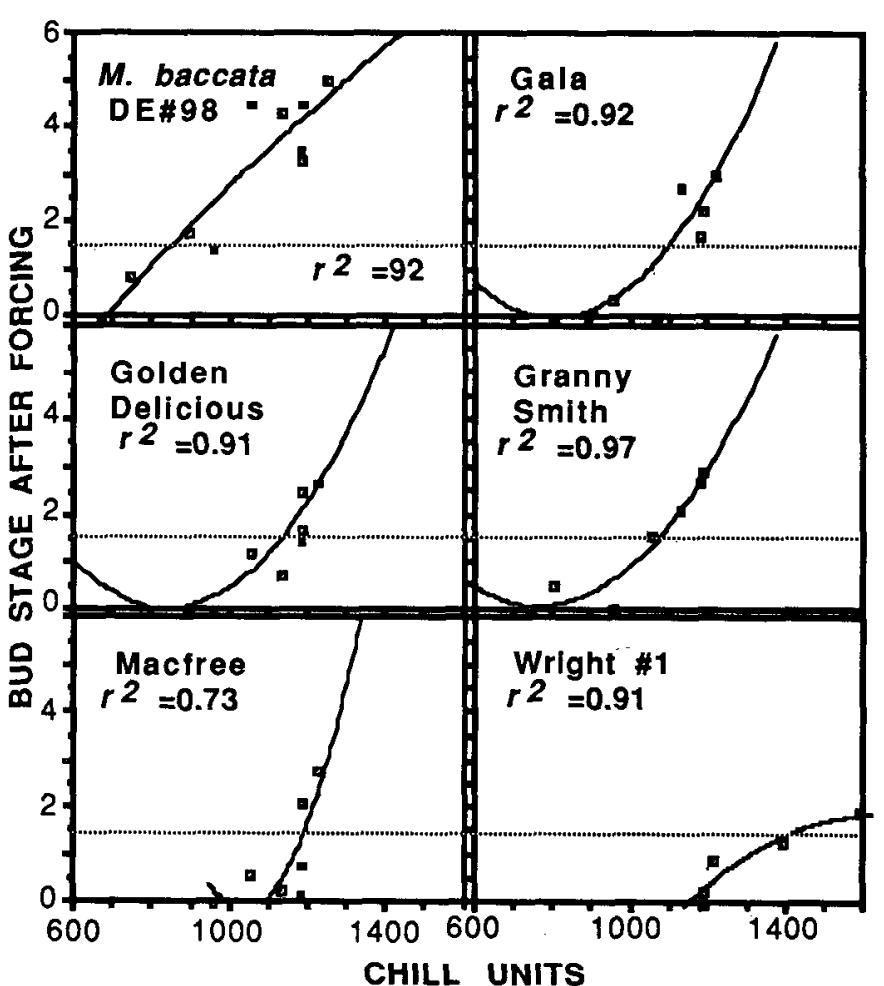

Fig. 6. Changes in the bud development stage after 21 days of forcing affected by both cultivar and total CU accumulation in the 1984-85 season. Seven bud development classes were assigned [based on Chapman and Catlin (1976)], where $0=$ dormant buds, $0.5=$ silvertip, 1 = greentip, 2 = half-inch green, 3 = tight cluster, 4 = pink, $5=$ bloom, and $6=$ petal fall (Hauagge and Cummins, 1991a).

Many of the wild species showed a pattern similar to that of M. baccata PI 392301 (Fig. 3), where dormancy intensity decreased continuously with $\mathrm{CU}$ accumulation. The time of budbreak at the first sampling date may reflect incomplete bud development rather than dormancy. From this result we concluded that excised shoots in which the terminal buds have been removed are not reliable for measuring bud dormancy intensity in apple.

Change in bud dormancy intensity and efficiency of chilling at the end of the dormancy period. Dormancy intensity declines at a high rate after maximum dormancy intensity is reached (Fig. 1), especially for cultivars that show accentuated dormancy intensity. There is some tendency to asymmetry of the $\mathrm{x}$ axis at the end of the rest period (Figs. 4 and 5). Even so, a seconddegree function fits well under these circumstances (Fig. 5), as has been reported previously (Couvillon and Erez, 1985; Hauagge and Cummins, 1991a). Genotypes differ in the rate and patterns at which dormancy dissipation takes place at the end of the rest period not only in relation to the D50 (Fig. 5), but also when other indicators of dormancy status, such as the bud developmental stage, are considered (Fig. 6).

Comparisons in the rates of change in dormancy intensity among genotypes could be made if they were considered in a similar stage of dormancy. This was done by considering relative $\mathrm{CU}$ accumulated as equal to zero when D50 occurred on the 15th day of forcing. This point was considered the end of the bud dormancy period (Hauagge and Cummins, 1991a). The second-degree equations for changes in dormancy intensity for the various apple genotypes were refitted. GDH (accumulated 
Table 3. Efficiency of the chilling effect in modifying GDH requirement for apple budbreak (GDH/ $\mathrm{CU})$. Quadratic function $(\mathrm{GDH} \times \mathrm{CU})$ was fitted considering $\mathrm{CU}=$ Oat the time when D50 occurred by the 15 th day of forcing. Data are presented as the derivative of that function at the points -200 , 0 , and $+200 \mathrm{CU}$ in the $1985-86$ and 1986-87 seasons. Probability of F for models was $>0.001$.

\begin{tabular}{|c|c|c|c|c|c|c|c|c|}
\hline \multirow[b]{3}{*}{ Cultivar/species } & \multicolumn{4}{|c|}{$1985-86$} & \multicolumn{4}{|c|}{$1986-87$} \\
\hline & \multirow[b]{2}{*}{$R^{\mathrm{z}}$} & \multicolumn{3}{|c|}{ Relative CU } & \multirow[b]{2}{*}{$R^{2}$} & \multicolumn{3}{|c|}{ Relative CU } \\
\hline & & -200 & 0 & +200 & & -200 & 0 & +200 \\
\hline Anna & 0.84 & -4.4 & -3.9 & -3.4 & 0.47 & -2.9 & -2.6 & -2.3 \\
\hline Anoka & & & & & 0.71 & -53.8 & -30.4 & -6.9 \\
\hline Arkad Zimnji & 0.87 & & -10.4 & -6.0 & 0.46 & -47.5 & -74.7 & \\
\hline Barbara Ann & 0.77 & & -9.2 & -4.9 & & & & \\
\hline Beverly Hills & 0.82 & & -6.7 & -5.6 & 0.94 & -38.6 & -19.3 & \\
\hline Blairmont & 0.74 & & -10.8 & -4.8 & 0.86 & -96.8 & -47.4 & \\
\hline Carla & & & & & 0.77 & -24.9 & -16.1 & -7.3 \\
\hline Cherry Cox & & & & & 0.93 & -83.2 & -33.6 & 16.1 \\
\hline Chihuahua Gold & & & & & 0.91 & -74.7 & -42.4 & -10.1 \\
\hline Coast & & & & & 0.57 & -7.3 & -12.9 & -18.6 \\
\hline Dakota & 0.87 & -17.7 & -11.3 & -4.9 & 0.87 & & -92.6 & 9.8 \\
\hline Delicious & 0.84 & -9.2 & -7.1 & -4.9 & 0.60 & -15.1 & -15.0 & -14.8 \\
\hline Dorsett Golden & & & & & 0.66 & -3.9 & -5.7 & -7.5 \\
\hline Early McIntosh & 0.76 & -5.8 & -6.3 & -6.7 & 0.94 & -21.5 & -15.3 & -9.1 \\
\hline Ein Shemer & 0.75 & -2.6 & -3.5 & -4.4 & 0.62 & -7.3 & -11.0 & -14.6 \\
\hline Elstar & 0.75 & -5.7 & -6 & -6.2 & & & & \\
\hline Empire & 0.92 & -12.8 & -8.4 & -4.0 & 0.91 & -85.0 & -48.7 & -12.5 \\
\hline Freyberg & & & & & 0.99 & -24.6 & -15.6 & -6.6 \\
\hline Fuji & 0.75 & & -7.1 & -4.3 & 0.82 & -65.4 & -29.9 & \\
\hline Gala & 0.80 & -6.5 & -6.0 & -5.5 & 0.83 & -94.0 & -52.6 & -11.3 \\
\hline Gallen & & & & & 0.62 & -96.0 & -48.8 & -1.6 \\
\hline Golden Delicious & 0.77 & -13.3 & -9.2 & -5.0 & 0.90 & -70.0 & -41.0 & -12.0 \\
\hline Governor Carr & ${ }^{2} 0.87$ & -3.6 & -4.1 & -4.6 & 0.73 & -9.5 & -16.1 & -22.7 \\
\hline Granny Smith & 0.70 & -8.1 & -6.1 & -4.0 & 0.43 & -17.0 & -20.7 & -24.4 \\
\hline Honeygold & 0.81 & -19.2 & -11.3 & -3.4 & 0.95 & -97.1 & -47.3 & 2.6 \\
\hline Hyslop & & & & & 0.7 & -85.4 & -42.3 & 0.8 \\
\hline Idared & 0.89 & -8.4 & -6.5 & -4.6 & 0.79 & -49.1 & -28.3 & -7.6 \\
\hline Ikorocavka Alaja & 0.82 & -10.9 & -8.1 & -5.3 & 0.52 & -32.4 & -30.9 & -29.3 \\
\hline Joan & 0.71 & & -4.8 & -4.6 & 0.69 & -11.9 & -18.8 & -25.6 \\
\hline June Wealthy & 0.77 & -5.7 & -5.8 & -6.0 & 0.54 & -35.9 & -29.7 & -23.6 \\
\hline Kerr & 0.91 & -4.7 & -4.8 & -4.8 & 0.82 & -91.1 & -48.9 & -6.8 \\
\hline Khashabi & 0.79 & -7.8 & -6.4 & -5.0 & & & & \\
\hline King Cole & 0.62 & -3.7 & -4.2 & -4.8 & 0.90 & -25 & -17.2 & -9.4 \\
\hline Koningszuụr & 0.84 & -3.0 & -5.7 & -8.5 & 0.95 & -61 & -21.3 & \\
\hline Lennoxville & 0.83 & & -7.2 & -5.1 & & & & \\
\hline Leyda & 0.81 & & -3.7 & -3.2 & 0.69 & -15.7 & -24.9 & -34.1 \\
\hline Liberty & 0.77 & -12.6 & -9.0 & -5.5 & 0.86 & -50.4 & -30.7 & -11.1 \\
\hline M. baccata Ge 24408 & 0.89 & -6.0 & -5.6 & -5.1 & 0.87 & -123.4 & -65.6 & -7.8 \\
\hline M. baccata Ge24911 & 0.85 & & -6.3 & -4.5 & 0.58 & -10.4 & -13.9 & -17.4 \\
\hline M. baccata DE\#98 & 0.88 & -5.4 & -4.9 & -4.3 & 0.41 & -16.7 & -17.2 & -17.8 \\
\hline M. baccata Nertschinsk & 0.96 & & -9.5 & -6.0 & 0.82 & -108.8 & -61.4 & -13.9 \\
\hline M. baccata PI 392301 & 0.86 & -4.7 & -4.3 & -4.0 & 0.77 & -3.0 & -4.8 & -6.6 \\
\hline M. baccata columnaris & 0.79 & -14.9 & -10.4 & -5.9 & 0.74 & -54.6 & -32.7 & -10.8 \\
\hline \multicolumn{9}{|l|}{ M. baccata } \\
\hline mandshurica & 0.87 & -9.0 & -6.9 & -4.7 & 0.85 & -8.4 & -9.5 & -10.7 \\
\hline M. brevipes & 0.90 & & -5.1 & -3.9 & 0.57 & 1.4 & -1.1 & -3.6 \\
\hline M. floribunda & 0.72 & & 1.5 & -0.1 & & & & \\
\hline M. prunifolia DE\#229 & 0.65 & -1.2 & -4.3 & -7.4 & 0.86 & -10.2 & -15.3 & -20.3 \\
\hline M. prunifolia Sikora I & 0.84 & -2.5 & -3.3 & -4.0 & 0.51 & -21.2 & -16.9 & -12.5 \\
\hline \multicolumn{9}{|l|}{ M. pninifolia } \\
\hline$\times$ anthocarpa & 0.74 & -3.8 & -4.6 & -5.4 & 0.89 & -5.7 & -8.2 & -10.6 \\
\hline M. rockii & 0.86 & & -1.9 & -2.5 & 0.76 & -5.5 & -6.2 & -6.8 \\
\hline M. spectabilis & 0.70 & -3.6 & -3.2 & -2.7 & 0.84 & -1.2 & -3.2 & -5.2 \\
\hline M. turesii 34143 & 0.92 . & & -5.1 & -4.2 & 0.94 & 14.7 & -11.7 & 8.7 \\
\hline M. $\times$ amoldiana & 0.95 & -6.8 & -5.4 & -4.1 & 0.88 & -9.4 & -8.4 & -7.4 \\
\hline M. $\times$ magdeburgensis & 0.78 & -3 & -3.4 & -3.8 & 0.93 & -10 & -8.7 & -7.3 \\
\hline M. $\times$ robusta DE\#485 & 0.87 & & -8.0 & -5.8 & 0.92 & -63.4 & -35.1 & -6.7 \\
\hline M. ×robusta Korea & & & & & 0.82 & -69 & -38.6 & -8.3 \\
\hline M. $\times$ robusta $\mathrm{R} 5$ & 0.83 & -4.4 & -4.5 & -4.6 & 0.69 & -56.2 & -30.8 & -5.4 \\
\hline
\end{tabular}




\begin{tabular}{|c|c|c|c|c|c|c|c|c|}
\hline \multirow[b]{3}{*}{ Cultivar/species } & \multicolumn{4}{|c|}{$1985-86$} & \multicolumn{4}{|c|}{$1986-87$} \\
\hline & \multirow[b]{2}{*}{$R^{\mathrm{z}}$} & \multicolumn{3}{|c|}{ Relative CU } & \multirow[b]{2}{*}{$R^{\mathrm{z}}$} & \multicolumn{3}{|c|}{ Relative CU } \\
\hline & & -200 & 0 & +200 & & -200 & 0 & 1200 \\
\hline \multicolumn{9}{|l|}{$\begin{array}{l}\text { M. } \times \text { scheideckeri } \\
\text { DE\#316 }\end{array}$} \\
\hline \multicolumn{8}{|l|}{ M. yunnanensis } & -9.5 \\
\hline Vilmorin & & & & & 0.76 & -23.8 & -15.8 & -7.9 \\
\hline M. zumi calocarpa & 0.79 & -6.8 & -6.2 & -5.6 & 0.92 & -80.0 & -45.1 & -10.2 \\
\hline Maribor & 0.68 & -19.5 & -11.8 & -4.1 & 0.83 & -57.5 & -32.1 & -6.6 \\
\hline Mclntosh & & & & & 0.81 & -126 & -49.2 & \\
\hline Medina & 0.91 & & -12.8 & -5.7 & 0.98 & -48.1 & -27.4 & -6.6 \\
\hline Melrose & 0.64 & & -11.1 & -6.8 & 0.85 & -44.4 & -27.6 & -10.9 \\
\hline Minkler & & & & & 0.92 & -101.6 & -46.2 & \\
\hline \multicolumn{5}{|l|}{ Mollie's Delicious } & 0.86 & -55.5 & -33.2 & -10.9 \\
\hline N.H. 9 & 0.72 & -12.3 & -8.1 & -3.8 & 0.75 & -17.8 & -24.4 & -31.1 \\
\hline N.J. 88 & 0.62 & & -9.8 & -3.9 & 0.94 & -47.0 & -25.8 & -4.6 \\
\hline Northern Spy & 0.73 & -7.4 & -6.6 & -5.9 & 0.81 & -73.2 & -36.7 & -0.3 \\
\hline \multicolumn{5}{|l|}{ NY 10} & 0.61 & -43.4 & -32.2 & -21.0 \\
\hline NY 330 & 0.69 & -9.6 & -7.0 & -4.5 & & & & \\
\hline NY 454 & 0.78 & & -10.6 & -4.8 & 0.94 & -25.4 & -16.8 & -8.1 \\
\hline NY 480 & 0.85 & -6.9 & -7.3 & -7.7 & 0.79 & -86.5 & -49.9 & -13.4 \\
\hline NY 485 & 0.64 & & -11.4 & -2.3 & 0.92 & -81.0 & -40.9 & -0.7 \\
\hline NY 506 & 0.86 & & -10.9 & -4.3 & 0.92 & -36.0 & -23.4 & -10.9 \\
\hline NY 543 & 0.74 & & -9.9 & -10.7 & 0.94 & -95.6 & -53.5 & -11.5 \\
\hline NY 615 & 0.87 & -12.8 & -8.1 & -3.5 & 0.93 & -33.2 & -21.6 & -10.0 \\
\hline NY 701 & 0.71 & & -6.1 & -5.5 & 0.84 & -67.8 & -39.3 & -10.8 \\
\hline NY 702 & 0.80 & & -8.0 & -10.7 & 0.53 & -35.2 & -33.4 & -31.6 \\
\hline NY 724 & 0.95 & & -11.5 & -6.0 & 0.59 & -15.4 & -15.3 & 15.1 \\
\hline NY 725 & ${ }^{\prime} 0.83$ & -14.6 & -9.8 & -4.9 & 0.92 & -33.9 & -21.4 & -9.0 \\
\hline Ottawa 7 & 0.82 & -5.5 & -5.1 & -4.7 & 0.94 & -17.7 & -13.2 & -8.7 \\
\hline Prima & 0.72 & -7.3 & -6.2 & -5.0 & 0.62 & -59.5 & -35.4 & -11.2 \\
\hline Priscilla & 0.81 & -6.3 & -6.4 & -6.5 & 0.95 & -32.5 & -19.5 & -6.4 \\
\hline Rome Beauty & & & & & 0.89 & -75.0 & -42.0 & -9.0 \\
\hline Rosedale & 0.92 & -3.7 & -4.1 & -4.6 & 0.64 & -14.4 & -11.8 & -9.3 \\
\hline Rozovoe & 0.89 & -11.5 & -8.5 & -5.5 & 0.95 & -39.0 & -24.6 & -10.1 \\
\hline \multicolumn{9}{|l|}{ Starspur Golden } \\
\hline Delicious & 0.69 & -88.1 & -45.0 & -2.9 & & & & \\
\hline Toba & 0.49 & -2.6 & -3.5 & -4.3 & 0.66 & -17.5 & -17.3 & -17.2 \\
\hline Transcendent & 0.89 & & -4.7 & -4.9 & 0.89 & -98.7 & -53.3 & -7.9 \\
\hline Vienna & 0.80 & & -6.7 & -4.8 & 0.85 & -63.0 & -33.9 & -4.8 \\
\hline Winter Banana & 0.79 & -2.9 & -3.4 & -3.9 & 0.87 & -9.0 & -9.4 & -9.8 \\
\hline Wright \#1 & 0.93 & -0.5 & -6.8 & -13.1 & 0.86 & -21.0 & -12.6 & -4.2 \\
\hline Yellow Newtown & & & & & 0.88 & -23.5 & -16.4 & -9.3 \\
\hline Zabaoani & 0.93 & -11.4 & -8.6 & -5.7 & 0.42 & -14.0 & -19.8 & -25.7 \\
\hline
\end{tabular}

${ }^{2}$ Coefficient of determination for the quadratic model.

in the field and during forcing) were used instead of days to budbreak. The derivative of each of the above equations, [d(GDH)/ $\mathrm{d}(\mathrm{CU})$ ], gives the instantaneous efficiency of the chilling effect in modifying the heat required to budbreak (GDH/CU). Absolute chilling efficiency values differed for the 1985-86 and 198587 seasons (Table 3), possibly because of forcing temperature differences $(23 \pm 1 \mathrm{C}$ and $19 \pm 1 \mathrm{C}$, respectively). However, it can be observed that the orders of magnitude within each year were similar. The smaller (or more negative) the values, the more capable is chilling in modifying the course of dormancy at this late stage. Chilling efficiency was negatively correlated with the length of bud dormancy (Table 4). This relationship illustrates that some low chillers are less responsive or respond differently to the action of low temperatures. The relationship also emphasizes the importance of factors other than chilling alone (Shaltout and Unrath, 1983) to terminate bud dormancy of cultivars that have short bud dormancy periods, especially those that are capable of doing well under subtropical conditions.
Clearly chill unit and heat unit requirements are dependent factors. The fixation of either one makes it possible to draw comparisons among genotypes. Heat requirement comparisons may be meaningless if the dormancy intensities of the genotypes are not taken into consideration.

Bud dormancy and time of spring budbreak. The time of apple budbreak in subtropical regions is directly related to the length of bud dormancy (Miller and Baker, 1982). It is a consequence of larger differences in heat requirement to budbreak in cultivars that have different bud dormancy patterns in an environment with limited CU accumulation (Figs. 2 and 4). Excessive $\mathrm{CU}$ accumulation in cold winter areas may bring the growth potential of different CR genotypes to very close levels (Fig. 4), and, consequently, the differences in time of budbreak among genotypes may become small. Even so, the length of bud dormancy plays a major role in determining the time of budbreak in the spring (Table 5) (Powell, 1986; Swartz and Powell, 1981). The efficiency by which chilling accumulation 
Table 4. Relationship between chilling effect in modifying the time of budbreak (GDH/CU) and CR of apple cultivars in the 1985-86 and 1986-87 seasons. Quadratic function $(\mathrm{GDH} \times \mathrm{CU})$ was fitted considering $\mathrm{CU}=0$ at the time when D50 occurred at either 15 or 20 days of forcing. Data are presented as the derivative of this function at -300 to +300 relative $\mathrm{CU}$ in relation to this point.

\begin{tabular}{|c|c|c|c|c|}
\hline \multirow{3}{*}{$\begin{array}{c}\text { Chilling } \\
\text { efficiency at } \\
\text { CU }\end{array}$} & \multicolumn{4}{|c|}{ Chilling requirement } \\
\hline & \multicolumn{2}{|c|}{$1985-86$} & \multicolumn{2}{|c|}{$1986-87$} \\
\hline & 20 days & 15 days & 20 days & 15 days \\
\hline-300 & & & $-0.32 * * *$ & $-0.08^{\mathrm{NS}}$ \\
\hline-200 & $-0.47^{* * *}$ & $-0.05^{\mathrm{NS}}$ & $-0.35^{* *}$ & $-0.10^{\text {NS }}$ \\
\hline-100 & $-0.55 * * *$ & $-0.19^{*}$ & $-0.36^{* * *}$ & $-0.11^{\mathrm{NS}}$ \\
\hline 0 & $-0.61 * * *$ & $-0.32 * *$ & $-0.41 * * *$ & $-0.18^{*}$ \\
\hline+100 & $-0.66^{* * *}$ & $-0.53^{* * *}$ & $-0.39 * * *$ & $-0.19^{*}$ \\
\hline+200 & $-0.40^{* * *}$ & $-0.57^{* * *}$ & $-0.18^{*}$ & $-0.21^{*}$ \\
\hline+300 & $0.19^{\mathrm{NS}}$ & $-0.02^{\mathrm{NS}}$ & $-0.32 * *$ & $-0.35^{* *}$ \\
\hline
\end{tabular}

Table 5. Correlation between the time of budbreak in Spring 1986 and 1987 and parameters related to the dormancy pattern development in the previous winter.

\begin{tabular}{llc}
\hline \hline & \multicolumn{2}{c}{ Time of field budbreak } \\
\cline { 2 - 3 } \multicolumn{1}{c}{ CR } & \multicolumn{1}{c}{1986} & 1987 \\
\hline D50-20 days & $0.59^{* * *}$ & $0.44^{* * *}$ \\
D50-15 days & $0.71^{\text {z***}}$ & $0.55^{* * *}$ \\
D50-10 days & $0.76^{* * *}$ & $0.60^{* * *}$ \\
D50-5 days & $0.69^{* * *}$ & $0.45^{* * *}$ \\
BDS-1.50 & $0.69^{* * *}$ & \\
BB-50\% & $0.45^{* *}$ & \\
\hline
\end{tabular}

zyx, $\mathrm{w}$ accumulated required to $50 \%$ budbreak within $20,15,10$, and 5 days of forcing, respectively.

${ }^{v} \mathrm{CU}$ accumulated required for buds to reach the stage of 1.5 (Hauagge and Cummins, 1991a) within 21 days of forcing.

"CU accumulated required to $50 \%$ terminal budbreak within 21 days of forcing.

$* *, * * *$ Significant at $P=0.01$ or 0.001 , respectively.

Table 6. Correlation between the time of budbreak in Spring 1987 and the chilling effect in modifying GDH requirement to budbreak (GDH/CU) (from Table 3).

\begin{tabular}{cc}
\hline \hline Chilling efficiency at CU & $\begin{array}{c}\text { Time of budbreak } \\
(1987)\end{array}$ \\
\hline-200 & $0.18^{\mathrm{Ns}}$ \\
$=100$ & $0.06^{\mathrm{NS}}$ \\
0 & $-0.04^{\mathrm{NS}}$ \\
+100 & $-0.23^{*}$ \\
+200 & $-0.42^{* * *}$ \\
\hline
\end{tabular}

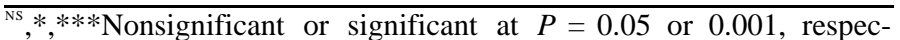
tively.

modifies the heat requirement for budbreak (Table 6) is another factor that interferes with the time of budbreak. Because of these factors, genotypes may interchange the ranking position on the intensity of bud dormancy (Fig. 4). This interchange may explain why the order of budbreak may vary when considering locations where $\mathrm{CU}$ accumulation differs. For instance, both 'Winter Banana' and M. rockii have relatively short and shallow dormancy periods, and yet budbreak in Geneva, N.Y., occurs substantially later than most commercial apple cultivars that have either a higher $\mathrm{CR}$ or deeper dormancy intensity. Budbreak of the same genotypes will occur very early in a subtropical environment (Hauagge and Cummins, 1991 b).

Gianfagna and Mehlenbacher (1985) suggested that apple cultivars may react differently to spring temperatures in activating budbreak. In fact, better correspondence between the dormancy developmental curve and budbreak in the field is sometimes observed when base temperatures other than the accepted optimum temperatures (Anderson et al., 1986) are used in the GDH calculations. Some cultivars, e.g., 'Elstar' and 'Winter Banana', may give a better fit when $10 \mathrm{C}$ is taken as the base temperature for GDH accumulation, and others (M. baccata and derivatives and other species) when $0 \mathrm{C}$ is used. This variation indicates that differences in the minimum activation temperature may play a role in the adaptation of Malus spp. and cultivars to warm and cold environments. However, additional data are needed to provide a clearer picture of this tendency.

\section{Literature Cited}

Amling, H.J. and K.A. Amling. 1980. Onset, intensity and dissipation of rest in several pecan cultivars. J. Amer. Soc. Hort. Sci. 105:536 540 .

Anderson, J. L., E.A. Richardson, and C.D. Kesner. 1986. Validation of chill unit and flower bud phenology models for 'Montmorency' sour cherry. Acts Hort. 184:71-78.

Bailey, J.S. 1948. A study of the rest period in red raspberries. Proc. Amer. Soc. Hort. Sci. 52:265-270.

Bowen, H.H. and G.W. Derickson. 1978. Rest prediction model for lowchilling 'Sungold' nectarine. J. Amer. Soc. Hort. Sci. 106:426-429.

Chandler, W.H. and D.S. Brown. 1957. Deciduous orchards in California winters. California Agr. Ext. Serv. Circ. 179.

Chapman, P.J. and G.A. Catlin. 1976. Growth stages in fruit treesfrom dormant to fruit set. N.Y. Food \& Life Sci. Bul. 58.

Couvillon, G.A. and A. Erez. 1985. Influence of prolonged exposure to chilling temperatures on bud break and heat requirement for bloom of several fruit species. J. Amer. Soc. Hort. Sci. 110:47-50.

Couvillon, G.A. and H. Hendershott. 1974. A characterization of the "after-rest" period of flower buds of two peach cultivars of different chilling requirements. J. Amer. Soc. Hort. Sci. 99:23-26.

Erez, A., G.A. Couvillon, and C.H. Hendershott. 1979. The effect of cycle length on chilling negation by high temperatures in dormant peach leaf buds. J. Amer. Soc. Hort. Sci. 104:573-576.

Fuchigami, L. H., M. Hotze, and C.J. Weiser. 1977. The relationship of vegetative maturity to rest development and spring bud-break. J. Amer. Soc. Hort. Sci. 102:450-452.

Gianfagna, T.J. and S.A. Mehlenbacher. 1985. Importance of heat requirement for bud break and time of flowering in apple. HortScience 20:909-911.

Hatch, A.H. and D.R. Walker. 1969. Rest intensity of dormant peach and apricot leaf buds as influenced by temperature, cold hardiness and respiration. J. Amer. Soc. Hort. Sci. 94:304-307.

Hauagge, R. and J.N. Cummins. 1991a. Relationships among indices for the end of bud dormancy in apple cultivars and related Malus species under cold winter conditions. J. Amer. Soc. Hort. Sci. 116:9599.

Hauagge, R. and J.N. Cummins. 1991b. Phenotypic variation of length of bud dormancy in apple cultivars and related Malus species. J. Amer. Sot. Hort. Sci. 116:100-106.

Hinesley, L.E. 1982. Dormancy in Abies fraseri seedlings at the end of the first growth cycle. Can J. For. Res. 12:374-383.

Jonkers, H. 1979. Bud dormancy of apple and pear in relation to the temperature during the growth period. Scientia Hort. 10:149-154.

Kobayashi, K. D., L.H. Fuchigami, and M.J. English. 1982. Modeling temperature requirements for rest development in Cornus sericea. J. Amer. Soc. Hort. Sci. 107:914-918.

Landsberg, J.J. 1974. Apple fruit bud development and growth: Analysis and an empirical model. Ann. Bet. 38:1013-1023.

Latimer, J.G. and H.A. Robitaille. 1981. Sources of variability in 
apple shoot selection and handling for bud rest determinations. J. Amer. Soc. Hort. Sci. 106:794-798.

Lavarenne, S., P. Barnola, and P. Champagnat. 1980. Climats artificiels et dormance des bourgeons 1. Temperatures et dormance automnale chez le frêne (Flaxinus excelsior L.). Compt. Rend. Acad. Agr. de France. 66:92-106.

Miller, E.P. and L.H. Baker. 1982. An evaluation of apple cultivars for Central and North Florida. Proc. Fla. State Hort. Sot. 95:88-90.

Mowrey, B.D. and W.B. Sherman. 1986. Relationship between autumn growth cessation and chilling requirement in peach. Fruit Var. J. 40:24-28.

Popenoe, W. and J.M. Benítez. 1965. Varieties of temperate zone fruits for tropical America. Proc. Carib. Reg. Amer. Soc. Hort. Sci.

$8: 118-129$.

Powell, L.E. 1986. The chilling requirement in apple and its role in regulating time of flowering in spring in cold-winter climates. Acts Hort. 179:129-139.

Samish, R.M. and S. Lavee. 1962. The chilling requirement of fruit trees. Proc. 16th Intl. Hort. Congr., Brussels. 5:372-388.

Scalabrelli, G. and G. A. Couvillon. 1986. The effect of temperature and bud type on rest completion and the $\mathrm{GDH}^{\circ} \mathrm{C}$ requirement for budbreak in 'Redhaven' peach. J. Amer. Soc. Hort. Sci. 111(4):537-540.
Shaltout, A.D. and C.R. Unrath. 1983. Rest completion prediction model for 'Starkrimson Delicious' apples. J. Amer. Soc. Hort. Sci. 108:957-961.

Stebbins, R.S. and L. Walheim. 1981. Western fruit, berries and nuts. How to select, grow and enjoy. H.P. Books, Los Angeles.

Swartz, H.J. and L.E. Powell, Jr. 1981. The effect of long chilling requirement on time of bud break in apple cultivars. Acts Hort. 120:173-178.

Tabuenca, M.C. 1983. Influencia de la temperature en la época de floración de dos variedades de manzano. Anal. Estación Expt. Aula Dei 16:341-346.

Tabuenca, M.C. and M.C. Jiménez. 1984. Efectos de distintas temperatures en otoño y en inveirno sobre dos variedades de manzanos. Anal. Estación Expt. Aula Dei 17:115-149.

Thompson, W. K., D.G. Nichols, and D.L. Jones. 1974. Chilling requirement of the apple cultivar Stoke Red. Austral. J. Expt. Agr. Animal Hush. 14:702-704.

Williams, R. R., G.R. Edwards, and B.G. Coombe. 1979. Determination of the pattern of winter dormancy in lateral buds of apples. Ann. Bet. (London) 44:575-581.

Worral, J. and F. Mergen. 1967. Environmental and genetic control of dormancy in Picea abies. Physiol. Plant. 20:733-745. 